\title{
Bouncing back or bouncing forward? Simulating urban resilience
}

1 A. Yair Grinberger

Department of Geography, Hebrew University of Jerusalem, Israel
2 Daniel Felsenstein $\mathrm{PhD}$

Department of Geography, Hebrew University of Jerusalem, Israel
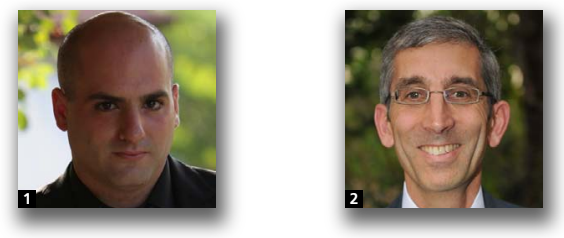

While the direct physical effects of an urban catastrophe are relatively straightforward to assess, indirect and longterm impact on the urban system is more circumspect. A large-scale shock such as an earthquake derails the complex urban system from its equilibrium path onto an unknown trajectory. Consequently, assessing the effect of policy intervention that aims to mitigate this shock and increase urban resilience is fraught with complexity. This paper presents the implementation of dynamic agent-based simulation to test long-run effects of a hypothetical earthquake in Jerusalem, Israel. It focuses on investigating the effectiveness of policy choices aimed at restoring the urban equilibrium. Cities are found to have a self-organising market-based mechanism that strives to attain a new equilibrium. They therefore may not always bounce back - they may also bounce forward. Decision-makers, engineers, emergency and urban planners need to be cognizant of this tendency when designing policy interventions. Otherwise, well-intentioned efforts may inhibit urban rejuvenation and delay the onset of city recovery.

\section{Introduction: understanding resilience}

Over the past few decades cities have been subjected to everincreasing disastrous events resulting in casualties and extensive property damage (Wamsler, 2004). As city populations and densities continue to rise, it is reasonable to assume that the trend of increasing damage from such events will intensify (Quarantelli, 1996; UNISDR, 2012). Given the magnitude of the potential catastrophes and also the expanding availability of data, tools and knowledge, increasing multidisciplinary effort is being focused on mediating the hazards facing cities and bolstering their resilience (Zolli and Healy, 2012). Much of this interest tends to focus on restoring urban conditions and rejuvenating city life. For engineers, the ability of the city to continue to restore critical services and maintain community capital in the aftermath of a catastrophic event, is a cornerstone of resilience. However, the issue of exactly what level of rejuvenation and for what purpose is often left vague. There is a general acceptance of a direct and linear cause and effect relationship in that a larger shock necessitates a larger effort to achieve restoration, and that time to recovery is somewhat proportionate to the magnitude of the disturbance (Chang and Rose, 2012).

This paper shows in the context of the long-term urban effects of an earthquake that such direct relationships are hard to justify. Efforts at promoting city resilience do not necessarily produce such causal outcomes. The reading of 'resilience' follows that common in ecology and engineering (Adger, 2000; Holling, 1996) and denotes the ability of a system (natural or constructed) to recover from a shock. While consciously focused on the notion of equilibrium urban growth, engineers recognise that the outcome of an unanticipated event is not predetermined, as multiple unstable equilbria may exist. Thus, a small and perhaps inocuous perturbation can tip the system from one equilibrium state to another. While shocks are invariably exogenous there is no knowing a priori which one is going to tilt the city or region onto a new growth path.

It has also been noted that nuanced but important differences exist as to whether this recovery is to a previous state, thereby assuming a single stable equilibrium (bouncing back) or whether the system post-shock has various trajectories for recovery and multiple potential equilibria (bouncing forward). 'Bouncing back' denotes the traditional occupation with regaining predisaster conditions (Chang, 2010). An urban disaster derails city development and it bounces back to a new growth path. In this case the counterfactual or city-growth-without-disaster state is not known. Furthermore, it is not known whether the current bounce-back is a permanent long-term adjustment. 'Bouncing 
Urban Design and Planning

Volume 167 Issue DP3
Bouncing back or bouncing

forward? Simulating urban

resilience

Grinberger and Felsenstein forward' observes how much disturbance the urban system can endure before it changes its structure. A key feature of postdisaster recovery is 'time compression' (Olshansky et al., 2012). This expresses the knee-jerk reaction in the aftermath of an unanticipated event. It is characterised by attempts to compress rebuilding activities such as renewal of capital stock, rebuilding of institutions, rejuvenating land use and commercial activity over a short period of time and in a focused area. The replacement of public housing with mixed affordability developments in post-Katrina New Orleans is a case in point (Olshansky et al., 2012).

However, different urban processes rejuvenate at different speeds: commercial activity can revive quickly while physical and social rebuilding needs a much longer time frame. This implies multiple and unstable urban equilibria and no linear causality between the size of the shock and type of rejuvenation. It also suggests no necessary congruence between the point of disaster and place of recovery. In addition, it illustrates that disaster can (perversely) offer opportunity for change and renewed growth. For example, the devastation wrought by World War II bombing on cities in Germany and Japan has been shown to have 'bounced forward' the economies of the devastated cities (Brakman et al., 2004; Davis and Weinstein, 2002).

This equilibrium view of resilience has been challenged in the context of urban recovery (Davoudi, 2012; Martin, 2012). The first claim is that cities are not as mechanistic and predictable as the equilibrium view purports. Second, recovery to a former state may not be a desired goal for those urban areas whose pre-disaster state was unattractive in the first place. Finally, the equilibrium view ignores 'the intentionality of human actions' (Davoudi, 2012: p. 305) implying that human intervention through regulation, planning and policy is effectively ignored.

Engineers acknowledge the existence of human intervention and test its effects in the realm of policy. In this context, policies have the potential to influence resilience. Specific policies may strive to re-establish damaged infrastructure and services, to control and direct flows, or initiate a change in the environment. A shock can therefore be used as an opportunity to improve the state of the city. Yet, cities are complex systems, which are not easy to predict and understand, especially when thrown out of balance by a disturbance. It is not surprising therefore that so much policy implementation fails to achieve expected outcomes, and sometimes even has the potential to exacerbate a disaster situation (Chamlee-Wright and Rothschild, 2007; Williams, 2008). This paper directly addresses this issue. It presents the results of a dynamic agent-based simulation that simulates an earthquake in an urban area and the possible policy responses to this shock. It highlights the direct and indirect effects of these human interventions and assesses their role in making cities more resilient.
The next section presents a non-technical overview of the agent-based simulation framework that was employed and its implementation in the real-world context of an earthquake centered on downtown Jerusalem. It then presents the basic indicators used to assess city resilience: time to recovery, land use rejuvenation and central business district (CBD) shift. The baseline conditions are simulated both with and without the joint effect of three policy options relating to human actions aimed at mediating the effect of the earthquake. These are tight land-use regulation, public provision of shelter for displaced citizens and the restoration of damaged public services. The outcomes of the policy interventions are highlighted and their implications for city resilience are discussed.

\section{Methodology}

Agent-based simulation decomposes the complexities of the urban system into the operation of 'agents'. These can be both individual entities such as citizens or aggregate institutions such as markets. In this context the key agents are households, workers, firms and local policy-makers. Each of these operates according to certain (programmable) behavioural rules, and in so doing affects the behaviour of other individual agents and in the aggregate the operation of urban institutions such as land and housing markets and the planning system. The urban system is particularly inflexible. This is because its morphology, which has accrued cumulatively over time, does not respond rapidly to change and because planned physical change is essentially a highly timedependent process with a long gestation lag. Furthermore, given the interconnectedness of agents, a shock to this system transferred through the aggregate behaviour of agents may have random spatial impacts. Given these temporal and spatial complexities, decision-makers have difficulty in fully comprehending the complexity of unanticipated events in urban areas.

Agent-based simulation is one way of demystifying this process. Figure 1 graphically outlines the components of the agent-based system serving this paper. This figure describes the different interdependencies between citizen agents and the urban environment. Exogenous and endogenous inputs (such as income level and migration probabilities) are used to characterise the decision process of the agents. This is also based on the conditions prevailing in the external environment and in turn affects this environment. The direct effects of both the shock and policy decisions are highlighted and point to the possible feedback responses as the direct effect of the shock begins to ripple through the system. A key characteristic of agent-based simulations is their reliance on simple behavioural rules. These dictate the simplified specification of agentenvironment interactions outlined in Figure 1.

\subsection{Simulating the urban environment}

The basic agent is the individual citizen, who under the constraints of the environment and individual attributes, 
Bouncing back or bouncing

forward? Simulating urban

resilience

Grinberger and Felsenstein

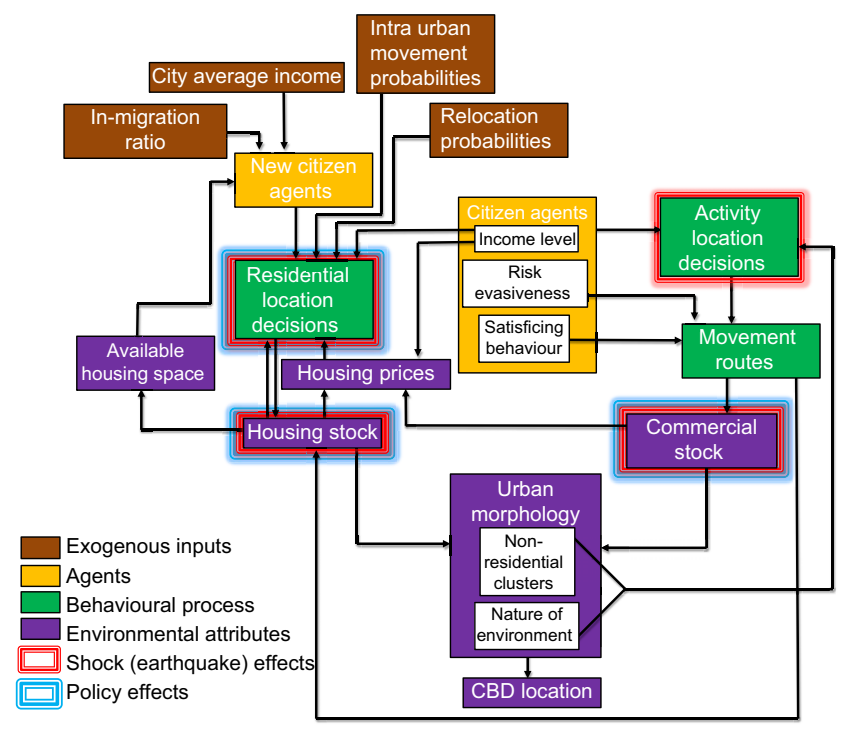

Figure 1. Agent-based conceptualisation of urban life. CBD, central business district

strives for a 'normal' existence; that is, an existence that satisfies certain predefined, behavioural objectives. These include maximising utility in terms of residence and participating in activities such as work, leisure, commercial and other social activities. Land use, which is represented by individual buildings, acts as a quasi-agent. While not mobile or able to act autonomously, it still reacts to actions of other agents, thereby changing the urban system. A shock to the system (such as an earthquake) and policy decisions to deal with this shock are exogenous (see Figure 1). While the spatial scale of the simulation can vary according to the needs of the task at hand, the temporal scale of the simulation is set to one iteration (i.e. the equivalent of 1 day). The simulation tool runs on the Repast Simphony platform, which is a popular Javabased development environment for agent-based simulations (Crooks and Castle, 2012).

\subsection{Citizen agents}

Figure 1 illustrates that agent behaviour consists of two kinds of decision-making - residential decisions and activity participation decisions. This paper attempts to make these as realistic as possible. Residence decisions are the first process undertaken each iteration (day). The citizen can decide to leave the current place of residence in favour of a location outside the city, or choose a different location within the city. These decisions are probabilistic and are based on the existing intra-urban movements and relocation probabilities at the neighbourhood scale. Out-migration rates are derived from the citywide out-migration/total population ratio. The choice of new building of residence is dependent on the availability of housing space and utility-maximising behaviour - the willingness to allocate one third of household income (derived from the average income in a spatial unit) to housing. The price of residential buildings is generated using a dynamic pricing system, in which the monthly cost of an apartment is derived from the value of the individual building in which it is located, which in turn is dependent on building floor space and average housing price in its neighbourhood. The latter changes with change in demand, supply and level of services. If an agent is unsuccessful in relocating within the city, due to lack of space or a high price/income ratio, it relocates outside the city.

Once all residential decisions are made, agents who outmigrate are removed from the simulation database, and the others continue to the second phase of decision-making. This relates to participation in activities. At each iteration, an agent may participate in up to three different activities, all of them located in one of the buildings in the study area with at least one being non-residential. Activities are associated with types of land use (residential or non-residential) and the choice of activity location is also probabilistic in nature. Each building has an attractiveness index based on its distance from the agent, the nature of its environment (the percentage of nonoccupied buildings in its surrounding area) and its floor space size (for non-residential uses only). If the attractiveness index exceeds a random value assigned to the agent (representing agent preference), then the building is visited. Agents sequence their activities and move between them on the road network, using a non-optimising, aerial distance-based route selection criteria. This results in satisficing behaviour (Simon, 1952) and reduces computing loads with respect to the alternative (i.e. optimisation). Agent behaviour also represents two further behavioural assumptions. The first is risk aversion, which is expressed in the tendency to avoid non-occupied buildings and shock-affected areas. The second relates to a preference for agglomeration, which is represented by a higher propensity to visit land uses that have greater floor space area.

\subsection{Urban dynamics}

Changes in land use are effected as follows: as commercial land-use is dependent on consumer flows and residential use on the presence of citizens, a deficit or surplus of agents may lead buildings to change their land use or to become unoccupied. The only use that is considered to be stable and insensitive to change is public use. The freedom of a building to switch land uses can be controlled by the user.

Four land-use change dynamics are considered: residential to commercial; commercial to unoccupied; residential to unoccupied; unoccupied to residential. The first two are dependent on consumer flows, represented by the volume of traffic (citizen 
Urban Design and Planning

Volume 167 Issue DP3
Bouncing back or bouncing

forward? Simulating urban

resilience

Grinberger and Felsenstein agents per day) on the road nearest to the location. This implies that revenue is proportionate to the number of visits, which is proportionate to nearby traffic volume. The traffic volume needed to sustain a commercial use is commensurate with floor space, so that larger buildings need to be near higher traffic loads. If the traffic volume does not satisfy this condition the building sheds its original use and is eligible for new uses. High traffic volumes may induce a change towards commercial use, again in proportion to floor space and nearby traffic volume. Citizens of buildings that become commercial make the choice between relocating and migrating. The third and fourth dynamics (residential to unoccupied and vice versa) are dependent on the number of residents within a building citizen agents may decide to move into an unoccupied building thereby changing its land use, or may leave a residential building, to the extent that it becomes abandoned.

Agents can also affect urban dynamics through the creation of available housing, which induces in-migration. The city starts initially as fully occupied and the volume of in-migration is dependent on changes in residential stock, as housing space becomes available. The volume of in-migration is proportional to the amount of available housing spaces, through the inmigration/total population ratio, but some variance is allowed in order to facilitate changes in migration trends. Each potential citizen is added to the database only if they succeed in locating suitable available housing (where the monthly price is lower than a third of the agents' randomly generated, city average income).

\subsection{Exogenous inputs to urban dynamics}

Two key exogenous factors influence urban dynamics (Figure 1). The first is the single urban shock (i.e. the earthquake), which occurs on the fifth iteration of the simulation and is located randomly in space. The effect of the shock spreads outwards from the epicentre and decays exponentially. A resilience index is calculated for each building, in relation to its distance from the epicentre and its height. If a random number that is assigned to the building exceeds its resilience index, the building collapses. Its land use is annulled, residents lose their home and the nearest road becomes blocked for as long as the building remains in ruins. The duration of re-establishment is dependent on floor space size. Thus, although the earthquake is a one-time, static event, it directly impacts the land-use system and citizen behaviour.

Three exogenous policy options are also considered. These are all of a binary yes/no nature and relate to land-use regulation, sheltering policy and service replacement.

Land-use regulation policy: defines the freedom with which land use may change. In the absence of regulation, landuse changes are freely driven by the market. With regulation, no land-use change is allowed (with the exception of abandonment) and all rejuvenating land use simply replaces previous land use.

- Sheltering policy: in the absence of policy, citizens who lose their homes have an equal chance of migrating or relocating. In the presence of policy, they are concentrated in public buildings where they remain until their home is rebuilt. They can decide to relocate/migrate before this happens or may be displaced from their homes and will thus relocate/migrate.

- Service replacement policy: this is aimed at maintaining public services in the aftermath of the earthquake. When exercised, a similar sized commercial building replaces each public building that becomes damaged and remains as such until the original building is restored. In the absence of policy the level of services in the city decreases considerably.

The policies serve as a heuristic tool for testing the extent of urban resilience in the baseline (no-policy) case. They span the gamut of possible public intervention ranging from status quo to heavy-handed regulation. On this basis, it can be discerned whether resilience is expressed as bouncing back or bouncing forward. In principle, other more subtle policies could be articulated. However, the aim of this simulation exercise is demonstrative not exhaustive.

\subsection{Case study: earthquake in Jerusalem}

The simulation tool described above is demonstrated in respect to an earthquake in downtown Jerusalem (Figure 2). The city of Jerusalem, located $30 \mathrm{~km}$ southeast of the active Dead Sea fault line, has witnessed several major earthquakes, the last of which occurred in 1927. Although the centre of the

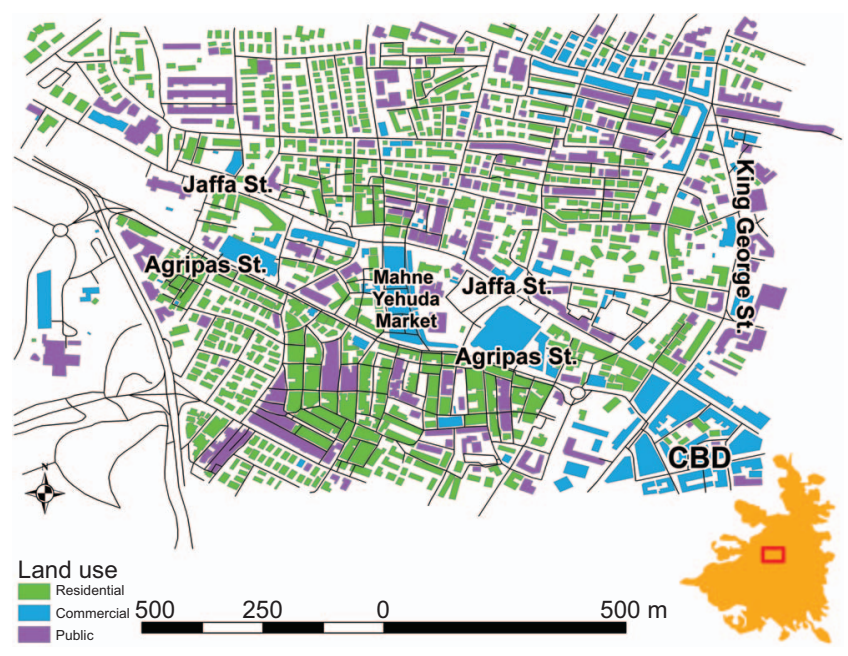

Figure 2. Study area. CBD, central business district 
city lies in a relatively stable area, thereby reducing natural hazard, the fact that many of the buildings within it were constructed before anti-seismic codes were established makes it prone to earthquake-related damage (Salamon et al., 2010). This is a unique mixed land-use area covering $1.45 \mathrm{~km}^{2}$ and characterised by low-rise buildings punctuated by high-rise structures. The area encompasses two major commercial spaces: the Mahaneh Yehuda enclosed street market and the city CBD. Three major transportation artery roads traverse the area with Agripas and Jaffa Streets (light railway route) running north-west to the south east, and King George Street running north-south. The area exhibits a heterogeneous mix of residential, commercial governmental and public land use and high traffic volumes.

Geographical information system (GIS) shapefiles are the basic input for the simulation and include disaggregate data for each building (i.e. floor space, land use, height). In order to assign agents and their socioeconomic attributes to buildings and obtain a spatially accurate representation of their distribution, statistical area (SA) data were disaggregated for population, income and household size to a per square metre base. (An SA is the finest level of spatial resolution for which census data are made available by the Israel Central Bureau of Statistics. It is a small homogenous unit containing approximately 3000 inhabitants.) The case study area comprises 19 SAs. Socioeconomic characteristics were then reassigned to the buildings based on their proportional floor sizes within the SA (see Lichter and Felsenstein (2012) for a detailed description of the method). The variables reassigned using this method are listed in Table 1.

Two scenarios were simulated: a no-intervention scenario (policy variables set to 'false') and a full intervention scenario (variables set to 'true'). The no-policy scenario generated the baseline conditions against which policy interventions were assessed. As the simulation requires intense computing resources, each scenario was simulated only 35 times, with each run consisting of 1000 iterations $(1000 \mathrm{~d})$. This rather arbitrary number of simulations was selected in order to balance computing requirements with the convergence of the results. For each run, the earthquake occurs randomly in space at day 5 in order to characterise effects that are not location dependent. The 5-d period was chosen in order to let nonearthquake-related urban mechanisms to reach full activity when the earthquake occurs. The results below relate to the averages for each scenario.

\section{Results}

As noted above, citizens are the main force driving urban dynamics in the model by moving, populating and affecting land uses. Accordingly, the sole purpose of a sheltering policy is to maintain original population levels in order to mitigate the loss of economic activity and to help residential stock to recover quickly. The first measure tested relates to change in total population size (Figure 3). Implementing policy intervention allows the city to return to close to pre-shock levels within a year but the no-policy simulation presents very similar outcomes and a return to a slightly higher equilibrium level. Over the long run, the two scenarios converge towards a trend of population decline, probably driven by the slow recovery rate of the residential stock and the concomitant rise in house prices that this generates.

Gross patterns of population change in the city do not, however, offer many insights into spatial change at the micro level and the way incremental actions by agents can lead to structural urban change. The effects of such change can be seen in Figures 4 and 5 and Table 2. Except for a few vulnerable large non-residential units, policy implementation stabilises the land-use system by regulating change and aiding the population. In contrast, the no-policy scenario presents a picture of a much more vulnerable commercial stock and an unstable

\begin{tabular}{llll}
\hline Aggregate measure & Scale & Value (simulation total) & Disaggregate measure \\
\hline Population size & SA & 2681 resident agents & Residents in building \\
Average income & SA & $6002 \cdot 54 \mathrm{NIS} /$ month & Income per citizen \\
Average household size & Citywide & $3 \cdot 4$ people/household & Non-residential building value \\
Capital stock value & Citywide & $40588658 \mathrm{NIS}$ & Residential building value \\
Average housing price/m & SA & $13840 \cdot 44 \mathrm{NIS} / \mathrm{m}$ & \\
Residential stock size & SA & 717 buildings & \\
Non-residential stock size & SA & 298 buildings & \\
Number of agents & SA & 2681 resident agents & \\
\end{tabular}

CBD, central business district; NIS, new Israeli shekels; SA, statistical area

Table 1. Aggregate and disaggregate variables 
Urban Design and Planning

Volume 167 Issue DP3
Bouncing back or bouncing

forward? Simulating urban

resilience

Grinberger and Felsenstein

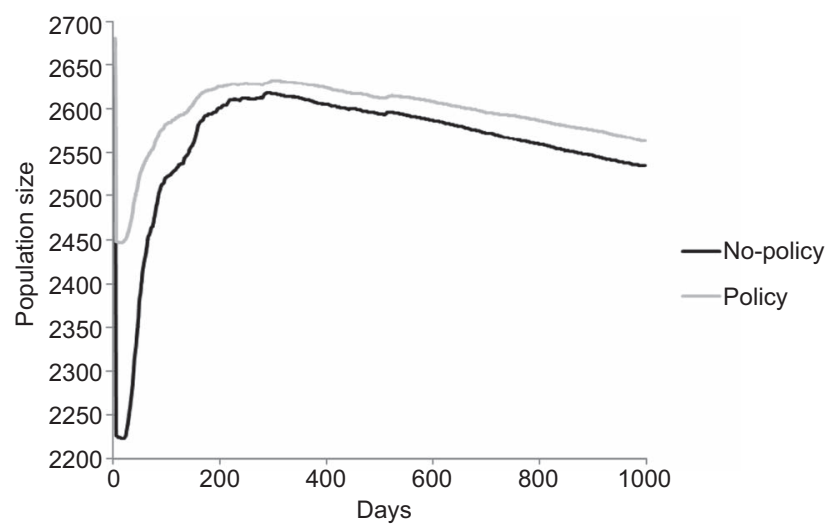

Figure 3. Change in population size, by time and scenario

residential stock more prone to high turnover rates, as reflected in the high frequencies of building use change (Figure 4).

The difference between the scenarios is more profound than mere destabilisation, as seen in changes to stock sizes and total values (Figure 5). While the policy scenario presents high levels of total non-residential stock value and low levels of residential stock value due to the lack of demand and to lower levels of services, the no-policy scenario presents an opposite picture, with a slow increase in stock size accompanying the decrease in non-residential values. Translated to average values, these results point to a decrease in average non-residential values and an increase in residential values in the no-policy scenario.
As floor space is one of the dominant elements in the calculation of building value, this finding is tantamount to stating that the average floor space size of non-residential buildings decreases and the opposite occurs in residential stock. This can be interpreted as evidence of the city bouncing forward to a new equilibrium in which commercial uses with abundant floor space cannot sustain themselves and become residential, while smaller residential uses identify the opportunity and switch to commercial use.

These changes reflect the change in the behaviour of individual agents. Change in commercial and housing stock is driven by the changing nature of traffic volumes. Agents who react to the shock change their travel patterns, thereby changing traffic volumes around the city and consequently affecting the ability of large commercial uses to sustain themselves. This leads to a new pattern of land use in the process of economic rejuvenation: in the aftermath of an earthquake small-scale convenience stores replace large commercial structures (malls) and apartment buildings replace family homes in the residential sector. Anecdotal empirical evidence of this tendency can be found in newspaper and internet media reports describing the aftermath of missile attacks on cities in southern Israel in 2012. See for example: 'Empty malls as consumers shop close to home', www.ynet.co.il, 18 November 2012.

A further issue relates not just to the form and pattern of landuse rejuvenation but whether an earthquake can affect urban function. A key indicator here is whether the magnitude of a shock causes shifts in the function and location of the CBD,

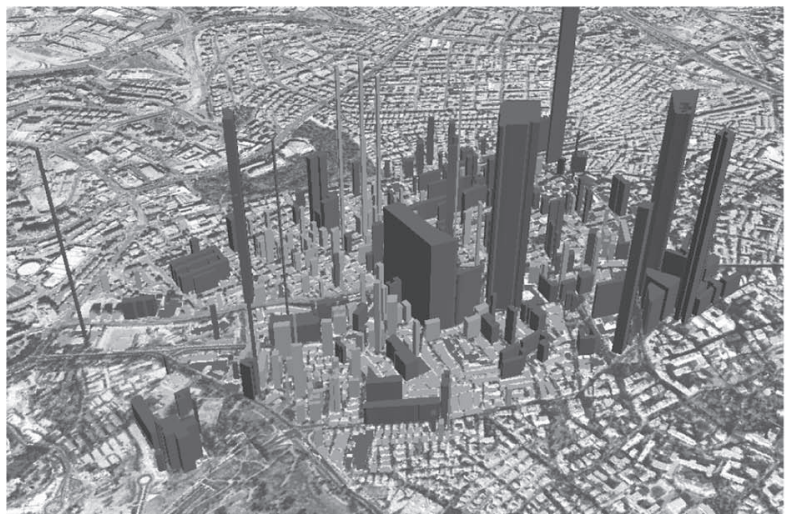

(a)

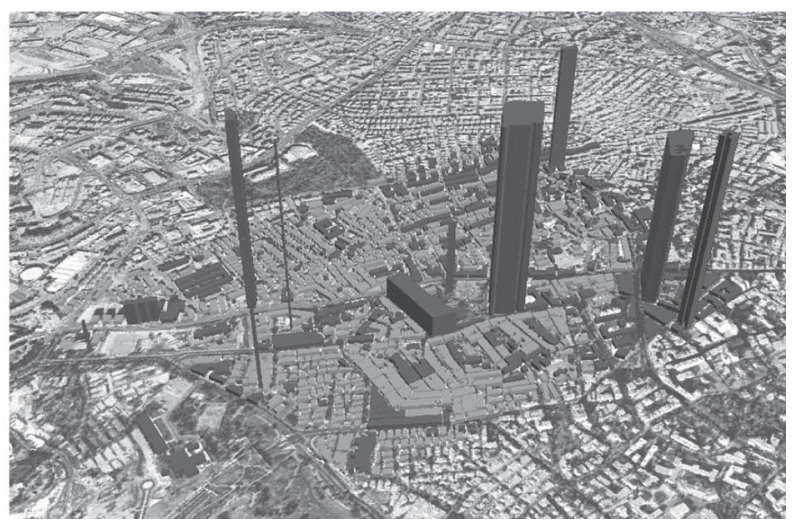

(b)

Figure 4. Frequency of change in land use for (a) no-policy scenario and (b) policy scenario. Height represents the number of simulation runs for each building in which the final land use was different from the initial one. Colour represents initial use: residential (light grey) and non-residential (dark grey) 


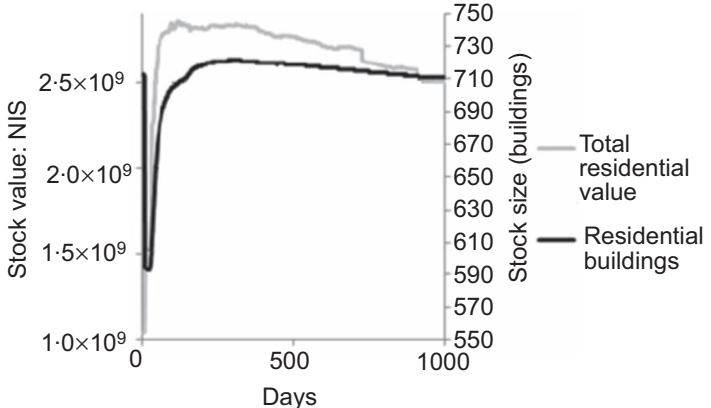

(a)

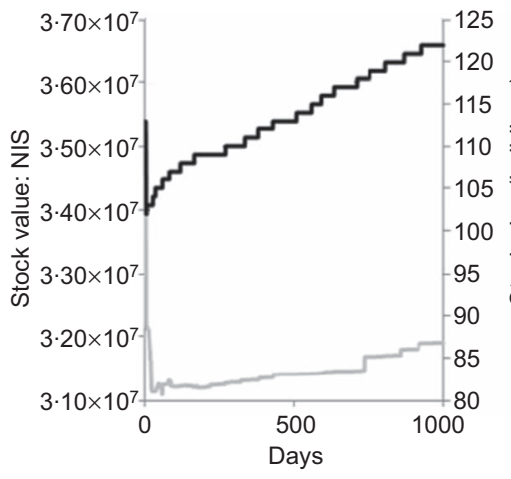

(c)

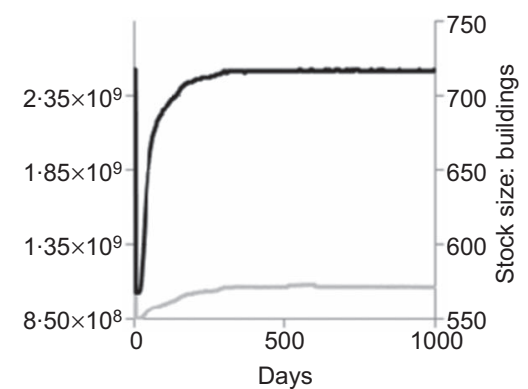

(b)

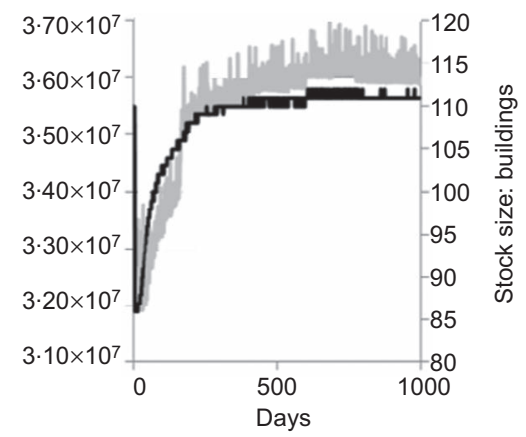

(d)

Figure 5. Changes in stock size and value, for residential (a) and nonresidential (b) capital stock in the no-policy scenario, and residential (c) and non-residential (d) stocks in the policy scenario. NIS, new Israeli shekels

thereby altering the urban centre of gravity. The magnitude of this shift is also an indicator of urban resilience. CBD vitality is measured as the CBD share of floor space out of total city floor space. The epicentre of the CBD is identified as a single building housing the maximum average of non-residential floor space (per building) in a specified radius $(250 \mathrm{~m})$. The sum of

\begin{tabular}{|c|c|c|c|c|c|}
\hline Scenario & State & $\mathrm{N}$ & $\begin{array}{l}\text { Average non- } \\
\text { residential floor space } \\
\text { around CBD: } \mathrm{m}^{2}\end{array}$ & $\begin{array}{l}\text { Total non-residential } \\
\text { floor space: } \mathrm{m}^{2}\end{array}$ & $\begin{array}{l}\text { CBD } \\
\text { movement: m }\end{array}$ \\
\hline & Initial state & 35 & $4575 \cdot 97$ & $924279 \cdot 59$ & $0 \cdot 00$ \\
\hline \multirow[t]{3}{*}{ No-policy } & Average final state: all & 35 & $3217 \cdot 63$ & $722116 \cdot 30$ & $20 \cdot 38$ \\
\hline & $\begin{array}{l}\text { Average final state: CBD } \\
\text { movement }\end{array}$ & 4 & $3421 \cdot 54$ & $726528 \cdot 41$ & $178 \cdot 33$ \\
\hline & $\begin{array}{l}\text { Average final state: no CBD } \\
\text { movement }\end{array}$ & 31 & $3191 \cdot 32$ & $721547 \cdot 00$ & $0 \cdot 00$ \\
\hline \multirow[t]{3}{*}{ Policy } & Average final state: all & 35 & $3940 \cdot 65$ & $804589 \cdot 79$ & $5 \cdot 10$ \\
\hline & $\begin{array}{l}\text { Average final state: CBD } \\
\text { movement }\end{array}$ & 1 & $3301 \cdot 20$ & $779024 \cdot 24$ & $178 \cdot 33$ \\
\hline & $\begin{array}{l}\text { Average final state: no CBD } \\
\text { movement }\end{array}$ & 34 & $3959 \cdot 45$ & $805341 \cdot 72$ & 0.00 \\
\hline
\end{tabular}

CBD, central business district

Table 2. Effects on CBD, by scenario 
the non-residential floor space in a radius of $250 \mathrm{~m}$ around the epicentre $(F S(b))$ is taken to denote CBD floor space.

$$
F S(b)=\frac{\sum_{i=1}^{n} F S(i)}{n}
$$

$F S(b)$ is the average amount of non-residential floor space in a distance of $250 \mathrm{~m}$ from building $b, F S(i)$ is the non-residential floor space of building $i, n$ is the number of buildings in a distance of $250 \mathrm{~m}$ from building $b$. A change in the identity of the building representing the $\mathrm{CBD}$ epicentre is indicative of the dispersal of commercial activity and a shift in the urban centre of gravity. Table 2 shows that while the urban system may reach a new state, such a change is rare and the basic functionality of the CBD is not easily shifted (maximum shifting of $20 \mathrm{~m}$ on average). CBD movement may be induced by an overall loss of commercial activity through migration of economic functions. The average floor space size measure shows that in the absence of policy there is rising average size around the $\mathrm{CBD}$, while in the policy case a decrease is witnessed in average size around the CBD. Therefore, only in the no-policy scenario is there evidence of a significant shift in the urban centre of gravity.

Finally, the paper attempts to test the nature of urban resilience. Does the city bounce back to a previous single state equilibrium or does it bounce forward to one of multiple potential equilibria? Evidence presented so far shows ambiguous trends, but these results only present a snapshot of a final state and do not tell the story in relation to stability and permanency of change. To investigate this issue various indicators of equilibrium are presented (Table 3). These estimate the ability to bounce back by returning to pre-shock values, and to bounce forward by attaining a new equilibrium. This is defined as preserving the same level of value for at least the last 50 simulated days.

These measures are presented in Table 3. They show the greatest divergence across the two scenarios and may represent the most significant findings. The role of policy as conceived here is to 'force' the city back to its pre-shock state. In other words, policies are designed to induce bouncing back. Success in this instance is indicated by the speed and frequency with which preshock values are restored. However, the equilibrium measures in Table 3 suggest that this recovery is not stable at all. With the exception of population size, equilibrium is rarely reached, with the highest frequency being nine of 35 times $(25 \cdot 7 \%)$ in the case of the effect of policy on average residential values. Even when it is attained, it appears much later than the return to previous values, with the minimum time lag being $670 \mathrm{~d}$. The no-policy scenario presents an opposite picture. While bouncing back is 
rarely achieved, with three measures reaching equilibrium one time or less, stabilisation by bouncing forward is much more frequently attained and requires a shorter span of time with a minimal frequency of 20 times $(57 \cdot 1 \%)$.

These findings suggest that the city has an inherent marketbased tendency to bounce forward to a new state. Wellintentioned policies aimed at changing this trajectory and restoring pre-shock conditions may ironically serve to inhibit urban resilience. The policy message from these results is that the one-size-fits-all policy prescription may not be suitable. Trying to force the city into some preferred recovery pattern may just retard the rejuvenation process. Policy implementation should try and avoid ready-made handbook solutions, and should rather focus on the specifics of the city, the nature of the shock and the likely growth trajectories derived from these.

\section{Conclusions}

Targeting policy is difficult to achieve at the best of times (Hansen, 1989). The situation is all the more complex when policy is harnessed to redirect an urban development trajectory in the aftermath of a disaster. Complex spatial dependencies between agents and markets mean that the effects of focused intervention may not end up where intended, and may even unintentionally generate a second round of 'recovery disaster' (Tierney, 2008). However, this does not mean that policy intervention should be eschewed. This paper presents a subtle message to the effect that cities are not helpless entities in the wake of a catastrophe. The results of the simulations, relating to impacts on the $\mathrm{CBD}$, land-use and stock value changes, and the stability of different equilibria, suggest that cities harbour an inherent selforganising mechanism that presupposes an ability for selfrecovery and promoting resilience. This mechanism does not necessarily direct the city back to its pre-shock state. As demonstrated above, a shock can result in bouncing forward to a new, commercially dispersed equilibrium.

In terms of urban planning and management praxis the implications are clear. Just as 'bouncing back' may not be the best recovery path for the city, 'bouncing forward' may also not offer an optimal strategy. Policy-makers and planners need to be able to assess potential bounce forward trajectories and to harness the self-organising mechanism that facilitates recovery. Policy decisions, therefore, should not be purely reactive to immediate needs. Intervention needs to be carefully and idiosyncratically crafted. In this respect, making cities more resilient is the thoughtful process of understanding urban dynamics and designing a tailor-made recovery process.

\section{Acknowledgement}

This research is based on work done in the Desurbs (Designing Safer Urban Spaces) research project funded by the European
Commission Seventh Framework Programme 2007-2013 under Grant Agreement No. 261652.

\section{REFERENCES}

Adger WN (2000) Social and ecological resilience: are they related? Progress in Human Geography 24(3): 247-364.

Brakman S, Garretsen H and Schramm M (2004) The strategic bombing of German cities during World War II and its impact on city growth. Journal of Economic Geography 4(2): 201-218.

Chamlee-Wright E and Rothschild D (2007) Disastrous Uncertainty: How Government Disaster Policy Undermines Community Rebound. Mercatus Policy Series, Policy Comment no. 9, Mercatus Center, George Mason University, VA, USA.

Chang SE (2010) Urban disaster recovery: a measurement framework and its application to the 1995 Kobe earthquake. Disasters 34(2): 303-327.

Chang SE and Rose AZ (2012) Towards a theory of economic recovery from a disaster. International Journal of Mass Emergencies and Disasters 32(2): 171-181.

Crooks AT and Castle CJ (2012) The integration of agent-based modeling and geographical information for geospatial simulation. In Agent-Based Models of Geographical Systems (Heppenstall AJ, Crooks AT, See LM and Batty M (eds)). Springer, The Netherlands, pp. 219-251.

Davis DR and Weinstein DE (2002) Bones, bombs and break points: the geography of economic activity. American Economic Review 92(5): 1269-1289.

Davoudi S (2012) Resilience: a bridging concept or a dead end? Planning Theory \& Practice 13(2): 299-307.

Hansen SB (1989) Targeting in economic development: comparative state perspectives. Publius 19(2): 47-62.

Holling CS (1996) Engineering resilience versus ecological resilience. In Engineering Within Ecological Constraints (Schulze PC (ed.)). National Academy Press, Washington, DC, USA, pp. 31-44.

Lichter M and Felsenstein D (2012) Assessing the costs of sea level rise and extreme flooding at the local level: a GIS-based approach. Ocean \& Coastal Management 59: 47-62.

Martin R (2012) Regional economic resilience, hysteresis and recessionary shocks. Journal of Economic Geography 12(1): $1-32$.

Olshansky RB, Hopkins LD and Johnson L (2012) Disaster and recovery: processes compressed in time. Natural Hazards Review 13(3): 173-178.

Quarantelli EL (1996) The future is not the past repeated: projecting disasters in the 21 st century from current trends. Journal of Contingencies and Crisis Management 4(4): 228240.

Salamon A, Katz O and Crouvi O (2010) Zones of required investigation for earthquake-related hazards in Jerusalem. Natural Hazards 53(2): 375-406. 
Simon H (1952) A behavioral model of rational choice. Quarterly Journal of Economics 69(1): 99-118.

Tierney K (2008) Hurricane in New Orleans? Who knew? Anticipating Katrina and its devastation. Sociological Inquiry 78(2): 179-183.

UNISDR (United Nations International Strategy for Disaster Reduction) (2012) How to Make Cities More Resilient - A Handbook for Local Government Leaders. UNISDR, Geneva, Switzerland.

Vale LJ and Campanella TJ (2005) The Resilient City: How
Modern Cities Recover from Disaster. Oxford University Press, New York, USA.

Wamsler C (2004) Managing urban risk: perceptions of housing and planning as a tool for reducing disaster risk. Global Built Environmental Review 4(2): 11-28.

Williams S (2008) Rethinking the nature of disaster: from failed instruments of learning to a post-social understanding. Social Forces 87(2): 1115-1138.

Zolli A and Healy AM (2012) Resilience: Why Things Bounce Back. Free Press, NY, USA.

\section{WHAT DO YOU THINK?}

To discuss this paper, please email up to 500 words to the editor at journals@ice.org.uk. Your contribution will be forwarded to the author(s) for a reply and, if considered appropriate by the editorial panel, will be published as discussion in a future issue of the journal.

Proceedings journals rely entirely on contributions sent in by civil engineering professionals, academics and students. Papers should be 2000-5000 words long (briefing papers should be 1000-2000 words long), with adequate illustrations and references. You can submit your paper online via www.icevirtuallibrary.com/content/journals, where you will also find detailed author guidelines. 